\title{
Palladium(II)-Catalyzed Oxidation of Pyrimidine Derivative by Hexacyanoferrate(III) in Aqueous Alkaline Medium: A Kinetic Study
}

\author{
Ahmed Fawzy ${ }^{1,2,}$, , Ishaq Zaafarany ${ }^{1}$, Fahd Turkistani ${ }^{1}$, Jabir Alfahemi ${ }^{1}$, Moataz Morad ${ }^{1}$ \\ ${ }^{1}$ Chemistry Department, Faculty of Applied Science, Umm Al-Qura University, Makkah, Saudi Arabia \\ ${ }^{2}$ Chemistry Department, Faculty of Science, Assiut University, Assiut, Egypt
}

Email address:

afsaad13@yahoo.com (A. Fawzy), iazaafarany@uqu.edu.sa (I. Zaafarany),drfahd999@gmail.com (F. Turkistani), jhfahemi@uqu.edu.sa (J. Alfahemi),mhmorad@uqu.edu.sa (M. Morad)

${ }^{*}$ Corresponding author

\section{To cite this article:}

Ahmed Fawzy, Ishaq Zaafarany, Fahd Turkistani, Jabir Alfahemi, Moataz Morad. Palladium(II)-Catalyzed Oxidation of Pyrimidine Derivative by Hexacyanoferrate(III) in Aqueous Alkaline Medium: A Kinetic Study. American Journal of Chemical Engineering. Vol. 4, No. 2, 2016 pp. 38-45. doi: 10.11648/j.ajche.20160402.12

Received: March 10, 2016; Accepted: March 18, 2016; Published: March 31, 2016

\begin{abstract}
The of kinetics of oxidation of a pyrimidine derivative, $N, N$-dimethyl- $N$ '-(pyrimidin-2-yl) formamidine (Pym-F), by hexacyanoferrate(III) (HCF) was studied in aqueous alkaline medium in the presence of palladium(II) catalyst. The reaction did not proceed in the absence of $\mathrm{Pd}(\mathrm{II})$ catalyst. The progress of the catalyzed reaction was followed spectrophotometrically. The reaction showed a first order kinetics in both [HCF] and [Pd(II)], and less than unit orders with respect to both [Pym-F] and $\left[\mathrm{OH}^{-}\right]$. Increasing ionic strength and dielectric constant of the medium increased the reaction rate. A mechanistic scheme for the catalyzed oxidation reaction has been proposed. The final oxidation products are identified as 2-aminopyrimidine, dimethylamine and carbon dioxide. The rate law expression associated with the reaction mechanism is derived and the reaction constants involved in the different steps of the mechanism are calculated. The activation parameters with respect to the ratedetermining step have been computed and discussed.
\end{abstract}

Keywords: Pyrimidine Derivative, Oxidation, Kinetics, Mechanism, Palladium(III), Hexacyanoferrate(III)

\section{Introduction}

Pyrimidine is a six-membered heterocyclic organic compound with two nitrogen atoms at positions 1 and 3 in the ring. The pyrimidine ring system has a wide occurrence in nature as substituted, ring fused compounds and derivatives, including the nucleotides, thiamine (vitamin B1) and alloxan [1]. It is also found in many synthetic compounds such as barbiturates and the HIV drug, zidovudine. Pyrimidine also photolytically decomposes into uracil under UV light [2]. Among the significant pyrimidine derivatives is $N, N$-dimethyl- $N$ '-(pyrimidin-2-yl) formamidine (Pym-F) where formamidines have attracted increasing interest in recent decades, because of their very broad spectrum of biological activities [3, 4]. The $N, N$-dialkyl derivatives of formamidines are highly effective acaricides and the most rewarding of these studies resulted in discovery of the acaricide insecticide chlordimeform [5, 6]. The oxidative cleavage of formamidines is quite important, since the $\mathrm{N}, \mathrm{N}$-dialkyl formamidine group is one of the most versatile protecting groups, especially in biosynthetic applications.

On the other hand, formamidines form complexes with transition metal ions [7,8] and such complexes exhibit remarkable biological activity against certain microbes, viruses and tumors $[9,10]$. The presence of heteroatom in such ligands plays a key role when coordinated with these metal ions such as pyrimidine derivatives. Furthermore, transition metal ions are used as catalysts in various oxidation-reduction reactions because they have various oxidation states [11-14].

Hexacyanoferrate(III) is an efficient one-electron oxidant for oxidation of various organic compounds especially in 
alkaline media [7, 8, 15-26]. The usefulness of HCF may be due to its high stability, water solubility and its moderate reduction potential of $0.45 \mathrm{~V}$, leading to its reduction to $\mathrm{HCF}(\mathrm{II})$, a stable product [27]. In addition, it adds less error to the experimental results, and data can be analyzed meticulously to establish the reaction path.

Although, the kinetics of the oxidation of Pym-F by permanganate ions have been studied in both alkaline [28] and acid [29] media, there are no reports describing its oxidation kinetics when other oxidants are used. This observation prompted us to investigate the title reaction. The aims of the present study are to establish the optimum conditions affecting oxidation of Pym-F by $\mathrm{HCF}$ in aqueous alkaline medium, to understand the active species of the reactants in such medium, to examine the catalytic activity of $\mathrm{Pd}(\mathrm{II})$ catalyst and finally to elucidate a plausible oxidation reaction mechanism.

\section{Experimental}

\subsection{Materials}

All chemicals used throughout the present work were of reagent grade and doubly distilled water was used in all preparations. The solution of Pym-F was freshly prepared by dissolving the sample in doubly distilled water. A solution of hexacyanoferrate(III) was prepared by dissolving potassium hexacyanoferrate(III) (BDH) in water and its concentration was ascertained spectrophotometrically. Hexacyanoferrate(II) solution was obtained by dissolving potassium hexacyanoferrate(II) (S.D fine Chem.) in water and standardizing with cerium(IV) solution [30]. The Palladium(II) chloride solution was prepared by dissolving a known weight of the sample (S.D fine Chem.) in hydrochloric acid and stored in a black coated bottle to prevent any photochemical deterioration. Sodium hydroxide, sodium perchlorate and $t$-butyl alcohol were used to vary the alkalinity, ionic strength and dielectric constant in the reaction medium, respectively.

\subsection{Kinetic Measurements}

Kinetic measurements were performed under pseudo-first order conditions where Pym-F was present in a large excess over over hexacyanoferrate(III) concentration at a constant ionic strength of $1.0 \mathrm{~mol} \mathrm{dm}^{-3}$ and at a constant temperature of $(25 \pm 0.1)^{\circ} \mathrm{C}$ unless otherwise stated. The progress of HCF reduction was followed by measuring the decay of its absorption spectrophotometrically at $\lambda_{\max }=420 \mathrm{~nm}$, its absorption maximum, where it absorbs to a considerably greater extent than any of the other reactants and products. It was also verified that there is no interference from other reagents at this wavelength. The spectrophotometer was Shimadzu UV-VIS-NIR-3600 double-beam. Solutions of the oxidant and the mixture containing Pym-F substrate, alkali and palladium(II) chloride catalyst were separately thermostated for nearly $30 \mathrm{~min}$. The oxidant was then added to the mixture, the overall reaction mixture was transferred to the cell of path length $1 \mathrm{~cm}$, and 3-4 experimental readings were taken in each run. It was observed that the oxidation reaction do not proceed in the absence of palladium(II) catalyst. Good straight lines for $\ln$ (absorbance) versus time plots were obtained for about two half-lives of the reaction completion. The pseudo-first order rate constants of the catalyzed reaction $\left(k_{\mathrm{C}}\right)$ were calculated as the gradients of such plots. The rate constants were reproducible to within $4 \%$. The order of reaction with respect to the reactants were determined from the slopes of $\log k_{\mathrm{C}}$ versus $\log$ (concentration) plots by varying the concentrations of substrate, alkali and catalyst, in turn, while keeping other conditions constant. A few kinetic runs were carried out after bubbling purified nitrogen and compared with those taken under air, and the results were found to be the same. Thus the dissolved oxygen did not have any effect on the oxidation rate.

\section{Results}

\subsection{Stoichiometry and Product Identification}

Reaction mixtures containing varying ratios of hexacyanoferrate(III) to Pym-F at a constant ionic strength of $1.0 \mathrm{~mol} \mathrm{dm}{ }^{-3}$ were kept for over $24 \mathrm{~h}$ at $25^{\circ} \mathrm{C}$ in a closed vessel for completion of the reaction. The unreacted [HCF] was analyzed spectrophotometrically by measuring its absorption at $420 \mathrm{~nm}$. The results indicated that two moles of $\mathrm{HCF}$ are consumed by one mole of Pym-F to yield the oxidation products as shown in the following stoichiometric equation:

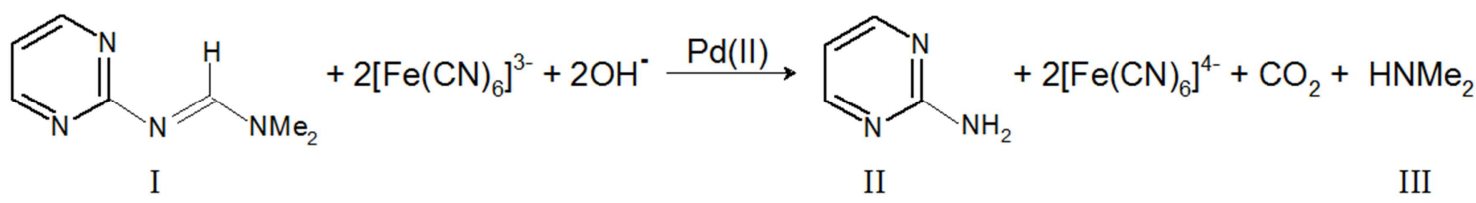

where compound I, II and III refer to Pym-F, 2aminopyrimidine and dimethylamine, respectively. The above stoichiometric equation is consistent with the results of product identification which carried out by spectral and elemental analysis as described elsewhere [28-32].

\subsection{Spectral Changes}

The spectral changes during the palladium(II)-catalyzed oxidation of Pym-F by HCF in aqueous alkaline medium are shown in Figure 1. The scanned spectra indicate gradual disappearance of HCF band with time at its absorption maximum, $\lambda=420 \mathrm{~nm}$, as a result of its reduction $\mathrm{HCF}(\mathrm{II})$. 


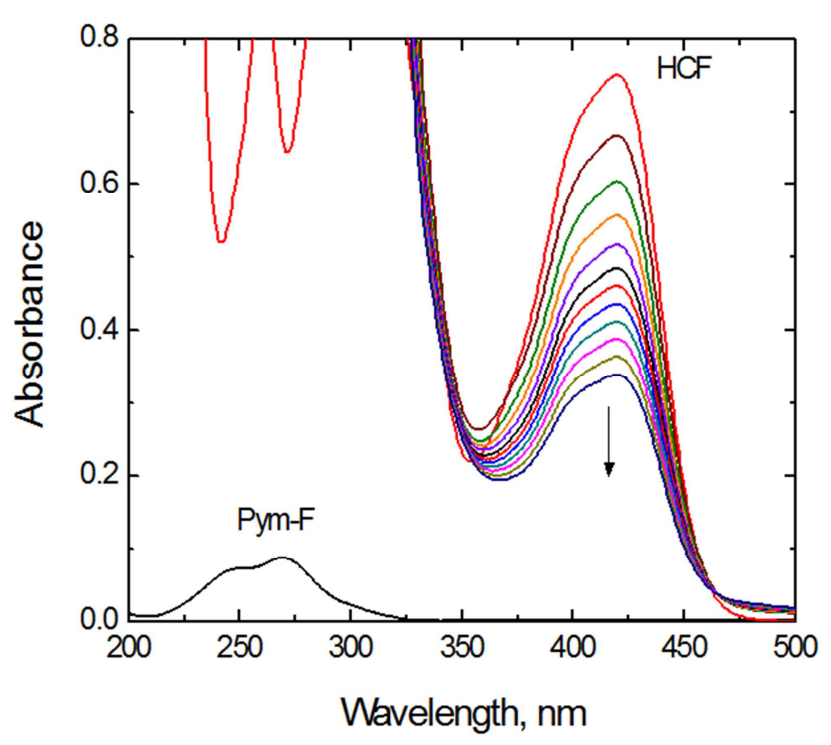

Figure 1. Spectral changes for Pd(II)-catalyzed oxidation of Pym-F by HCF in alkaline medium. $[\mathrm{Pym}-\mathrm{F}]=1.2 \times 10^{-2},[\mathrm{HCF}]=7.0 \times 10^{-4},\left[\mathrm{OH}^{-}\right]=0.5$, $[\mathrm{Pd}(\mathrm{II})]=6.0 \times 10^{-5}$ and $\mathrm{I}=1.0 \mathrm{~mol} \mathrm{dm}{ }^{-3}$ at $25^{\circ} \mathrm{C}$. Scanning time intervals $=$ $4.0 \mathrm{~min}$.

\subsection{Dependence of the Reaction Rate on [HCF]}

HCF concentration was varied in the range of $(1.0-11.0)$ $\mathrm{x} 10^{-4} \mathrm{~mol} \mathrm{dm}^{-3}$ at constant concentrations of other reagents and constant ionic strength and temperature. The plots of $\ln$ (absorbance) versus time were linear for about two halflives of the reaction completion. Furthermore, the pseudofirst order rate constant, $k_{\mathrm{C}}$, was found to be independent of the initial concentration of HCF (Table 1). These results suggest first order dependence of the reaction on [HCF].

\subsection{Dependence of the Reaction Rate on [Pym-F]}

The reaction rate was measured at different concentrations of the Pym-F substrate keeping other reactant concentrations constant. The plot of $k_{\mathrm{C}}$ versus [Pym-F] was found to be linear with a positive intercept (Figure 2) indicating that the reaction order with respect to $[\mathrm{Pym}-\mathrm{F}]$ was found to be less than unity.

\subsection{Dependence of the Reaction Rate on [OH]}

The effect of $\mathrm{pH}$ on the reaction rate was studied by varying the concentration of $\mathrm{NaOH}$ in the range of 0.1 $1.0 \mathrm{~mol} \mathrm{dm}^{-3}$ at constant [Pym-F], [HCF], [Pd(II)], ionic strength and temperature. An increase in alkali concentration was found to accelerate the oxidation rate (Table 1) indicating that the oxidation process was base-catalyzed. A plot of $\log k_{\mathrm{C}}$ versus $\log \left[\mathrm{OH}^{-}\right]$was found to be linear with a slope of 0.56 suggesting that the reaction was fractional-first order with respect to $\left[\mathrm{OH}^{-}\right]$as shown in Figure 3.

\subsection{Dependence of the Reaction Rate on [Pd(II)]}

The palladium(II) catalyst concentration was varied from $2.0 \times 10^{-5}$ to $12.0 \times 10^{-5} \mathrm{~mol} \mathrm{dm}{ }^{-3}$ at constant [Pym-F], [HCF], $\left[\mathrm{OH}^{-}\right]$and at constant ionic strength and temperature.
Reaction rate was found to increase with increasing [Pd(II)] (Table 1). The order with respect to [Pd(II)] was found to be unity as the slope of $\log k_{\mathrm{C}}$ versus $\log [\mathrm{Pd}(\mathrm{II})]$ plot (Figure 4).

\subsection{Dependence of the Reaction Rate on Ionic Strength and Dielectric Constant}

The ionic strength was varied from 1.0 to $3.0 \mathrm{~mol} \mathrm{dm}^{-3}$ using sodium perchlorate at constant concentrations of Pym$\mathrm{F}, \mathrm{HCF}, \mathrm{Pd}(\mathrm{II})$ and at constant $\mathrm{pH}$ and temperature. Increasing the ionic strength increased the reaction rate (Table 1). The Debye-Huckel plot was found to linear with a positive intercept, Figure 5.

To investigate the effect of the dielectric constant, $D$, of the reaction medium on the rate, the reaction was studied at different solvent compositions of $t$-butyl alcohol and water by varying the alcohol content from 0 to $40 \%(\mathrm{~V} / \mathrm{V})$ in the reaction medium at constant other variables. The results indicate that the reaction rate decreased with decreasing the dielectric constant of the medium, i.e, increasing the alcohol content and the plot of $k_{\mathrm{C}}$ versus $1 / D$ was found to linear with a negative intercept as illustrated in Figure 6.

Table 1. Effect of variation of [HCF], [Pym-F], [OH], [Pd(II)] and ionic strength (I) in the pseudo-first order rate constant $\left(k_{C}\right)$ in the Pd(II)catalyzed oxidation of Pym-F by $\mathrm{HCF}$ in alkaline medium at $25^{\circ} \mathrm{C}$.

\begin{tabular}{|c|c|c|c|c|c|}
\hline $\begin{array}{l}10^{4}[\mathrm{HCF}] \\
\left(\mathrm{mol} \mathrm{dm}^{-3}\right)\end{array}$ & $\begin{array}{l}10^{2}[\mathrm{Pym}-\mathrm{F}] \\
\left(\mathrm{mol} \mathrm{dm}^{-3}\right)\end{array}$ & $\begin{array}{l}{\left[\mathrm{OH}^{-}\right]} \\
\left(\mathrm{mol} \mathrm{dm}^{-3}\right)\end{array}$ & $\begin{array}{l}10^{5}[\mathrm{Pd}(\mathrm{II})] \\
\left(\mathrm{mol} \mathrm{dm}^{-3}\right)\end{array}$ & $\begin{array}{l}I \\
\left(\mathrm{~mol} \mathrm{dm}^{-3}\right)\end{array}$ & $\begin{array}{l}10^{3} k_{\mathrm{C}} \\
\left(\mathrm{s}^{-1}\right)\end{array}$ \\
\hline 1.0 & 1.6 & 0.5 & 6.0 & 1.0 & 21.4 \\
\hline 3.0 & 1.6 & 0.5 & 6.0 & 1.0 & 20.9 \\
\hline 5.0 & 1.6 & 0.5 & 6.0 & 1.0 & 22.1 \\
\hline 7.0 & 1.6 & 0.5 & 6.0 & 1.0 & 21.6 \\
\hline 9.0 & 1.6 & 0.5 & 6.0 & 1.0 & 21.3 \\
\hline 11.0 & 1.6 & 0.5 & 6.0 & 1.0 & 22.0 \\
\hline 7.0 & 0.4 & 0.5 & 6.0 & 1.0 & 9.0 \\
\hline 7.0 & 0.8 & 0.5 & 6.0 & 1.0 & 16.1 \\
\hline 7.0 & 1.2 & 0.5 & 6.0 & 1.0 & 22.6 \\
\hline 7.0 & 1.6 & 0.5 & 6.0 & 1.0 & 29.9 \\
\hline 7.0 & 2.0 & 0.5 & 6.0 & 1.0 & 36.2 \\
\hline 7.0 & 2.4 & 0.5 & 6.0 & 1.0 & 41.0 \\
\hline 7.0 & 1.6 & 0.1 & 6.0 & 1.0 & 10.2 \\
\hline 7.0 & 1.6 & 0.3 & 6.0 & 1.0 & 18.3 \\
\hline 7.0 & 1.6 & 0.5 & 6.0 & 1.0 & 22.6 \\
\hline 7.0 & 1.6 & 0.7 & 6.0 & 1.0 & 28.6 \\
\hline 7.0 & 1.6 & 0.9 & 6.0 & 1.0 & 33.2 \\
\hline 7.0 & 1.6 & 1.0 & 6.0 & 1.0 & 35.1 \\
\hline 7.0 & 1.6 & 0.5 & 2.0 & 1.0 & 8.2 \\
\hline 7.0 & 1.6 & 0.5 & 4.0 & 1.0 & 15.9 \\
\hline 7.0 & 1.6 & 0.5 & 6.0 & 1.0 & 22.6 \\
\hline 7.0 & 1.6 & 0.5 & 8.0 & 1.0 & 30.2 \\
\hline 7.0 & 1.6 & 0.5 & 10.0 & 1.0 & 37.8 \\
\hline 7.0 & 1.6 & 0.5 & 12.0 & 1.0 & 45.3 \\
\hline 7.0 & 1.6 & 0.5 & 6.0 & 1.0 & 22.6 \\
\hline 7.0 & 1.6 & 0.5 & 6.0 & 1.4 & 25.7 \\
\hline 7.0 & 1.6 & 0.5 & 6.0 & 1.8 & 28.4 \\
\hline 7.0 & 1.6 & 0.5 & 6.0 & 2.2 & 31.2 \\
\hline 7.0 & 1.6 & 0.5 & 6.0 & 2.6 & 35.5 \\
\hline 7.0 & 1.6 & 0.5 & 6.0 & 3.0 & 39.2 \\
\hline
\end{tabular}

Experimental error $\pm 3 \%$ 


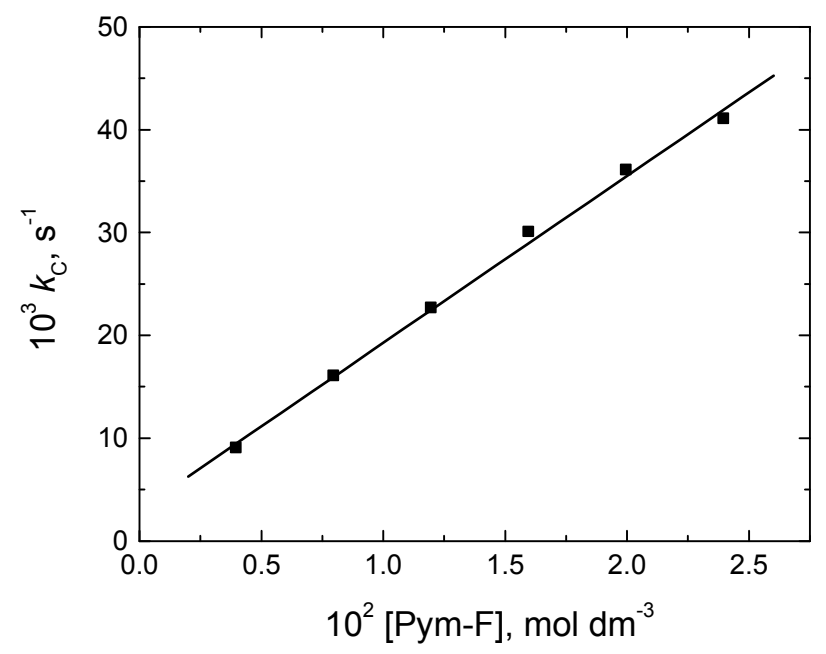

Figure 2. Plot of $k_{C}$ versus $[$ Pym-F] in the Pd(II)-catalyzed oxidation of Pym-F by HCF in alkaline medium. $[\mathrm{HCF}]=7.0 \times 10^{-4},[\mathrm{OH}]=0.5$, $[P d(I I)]=6.0 \times 10^{-5}$ and $I=1.0 \mathrm{~mol} \mathrm{dm} m^{-3}$ at $25^{\circ} \mathrm{C}$.

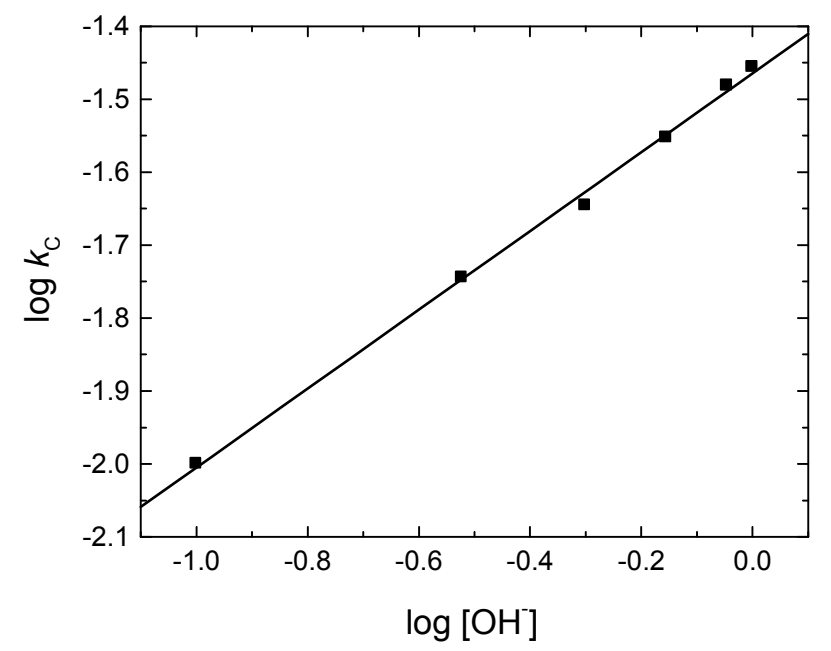

Figure 3. Plot of $\log k_{C}$ versus $\log [\mathrm{OH}]$ in the Pd(II)-catalyzed oxidation of Pym- $F$ by $H C F$ in alkaline medium. $[H C F]=7.0 \times 10^{-4},[P y m-F]=1.2 \times 10^{-}$ ${ }^{2},[P d(I I)]=6.0 \times 10^{-5}$ and $I=1.0 \mathrm{~mol} \mathrm{dm}{ }^{-3}$ at $25^{\circ} \mathrm{C}$.

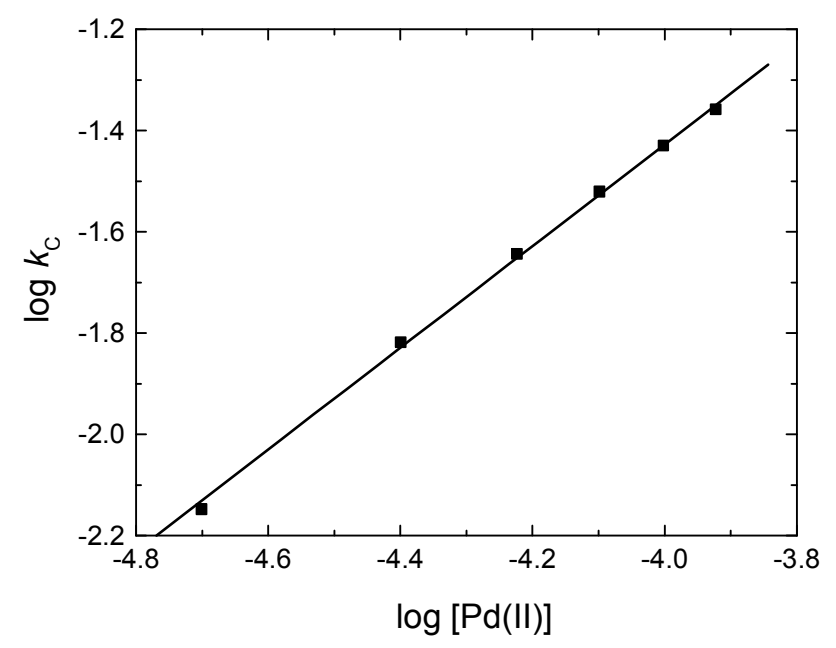

Figure 4. Plot of $\log k_{C}$ versus $\log [P d(I I)]$ in the Pd(II)-catalyzed oxidation of Pym-F by HCF in alkaline medium. $[H C F]=7.0 \times 10^{-4},[P y m-F]=1.2 x$ $10^{-2},\left[\mathrm{OH}^{\top}\right]=0.5$ and $\mathrm{I}=1.0 \mathrm{~mol} \mathrm{dm} \mathrm{m}^{-3}$ at $25^{\circ} \mathrm{C}$.

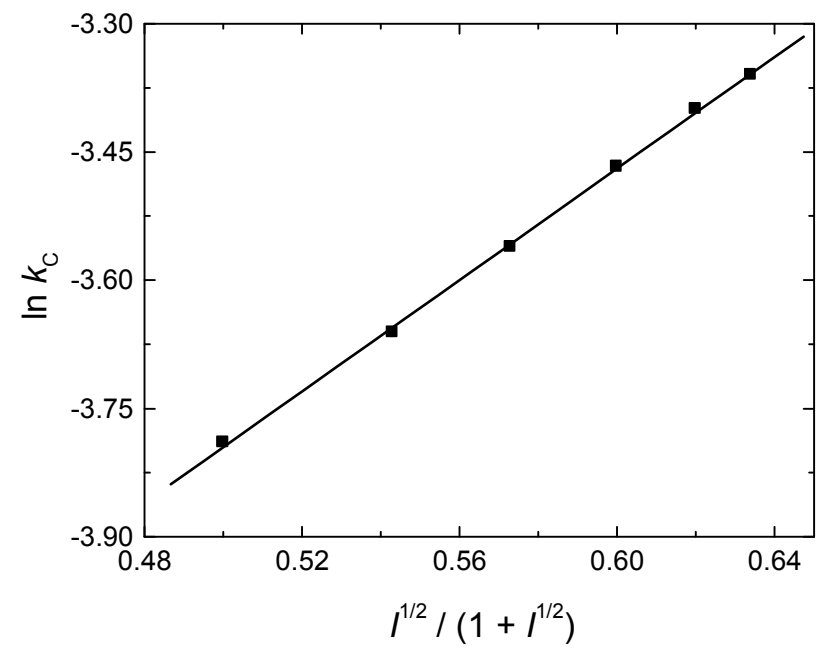

Figure 5. Debye-Huckel plot in the Pd(II)-catalyzed oxidation of Pym-F by $\mathrm{HCF}$ in alkaline medium. $[\mathrm{HCF}]=7.0 \times 10^{-4},[\mathrm{Pym}-\mathrm{F}]=1.2 \times 10^{-2},[\mathrm{OH}]=$ 0.5 and $[P d(I I)]=6.0 \times 10^{-5} \mathrm{~mol} \mathrm{dm}^{-3}$ at $25^{\circ} \mathrm{C}$.

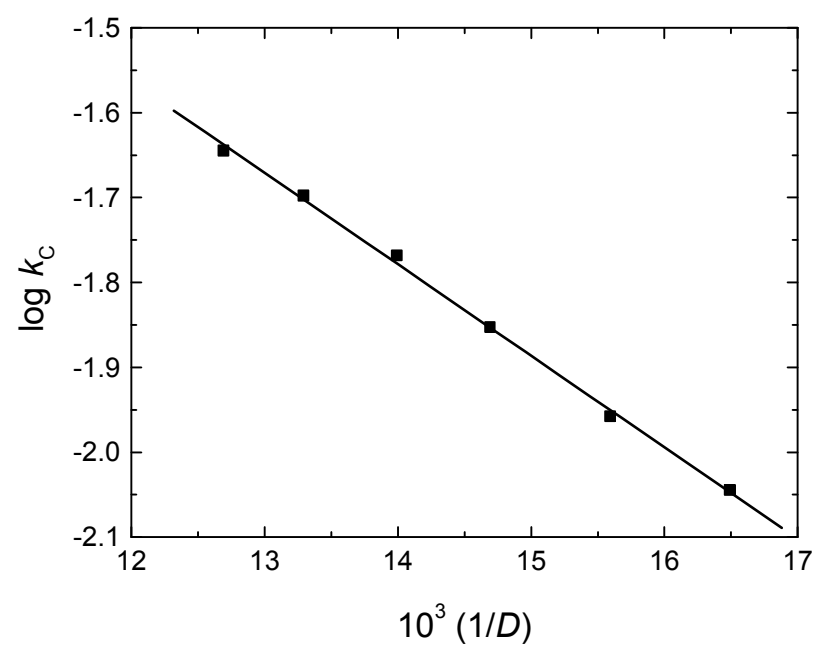

Figure 6. Effect of dielectric constant on the oxidation rate in the Pd(II)catalyzed oxidation of Pym-F by HCF in alkaline medium. $[H C F]=7.0 x$ $10^{-4},[\mathrm{Pym}-\mathrm{F}]=1.2 \times 10^{-2},[\mathrm{OH}]=0.5,[\mathrm{Pd}(\mathrm{II})]=6.0 \times 10^{-5}$ and $I=1.0 \mathrm{~mol}$ $d m^{-3}$ at $25^{\circ} \mathrm{C}$

\subsection{Effect of Temperature}

The $\mathrm{Pd}(\mathrm{II})$-catalyzed reaction was studied at four temperatures ranging between 288 and $318 \mathrm{~K}$ at constant substrate, alkali and $\mathrm{Pd}(\mathrm{II})$ concentrations. The oxidation rate was found to increase with raising temperature. The activation parameters were evaluated using Arrhenius and Eyring plots and are listed in Table 2.

Table 2. Activation parameters associated with the slow step $(k)$ in the $P d(I I)$-catalyzed oxidation of Pym-F by HCF in alkaline medium. $[P y m-F]=$ $1.2 \times 10^{-2},[\mathrm{HCF}]=7.0 \times 10^{-4},[\mathrm{OH}]=0.5,[\mathrm{Pd}(\mathrm{II})]=6.0 \times 10^{-5}$ and $I=1.0$ $\mathrm{mol} \mathrm{dm^{-3 }}$.

\begin{tabular}{llll}
\hline $\begin{array}{l}\Delta \mathbf{S}^{\ddagger} \\
\mathbf{J ~ m o l}^{-1} \mathbf{K}^{-\mathbf{1}}\end{array}$ & $\begin{array}{l}\boldsymbol{\Delta} \mathbf{H}^{\ddagger} \\
\mathbf{k J} \mathbf{~ m o l}^{-\mathbf{1}}\end{array}$ & $\begin{array}{l}\boldsymbol{\Delta} \mathbf{G}^{\ddagger}{ }_{298} \\
\mathbf{k J} \mathbf{~ m o l}^{\mathbf{1}}\end{array}$ & $\begin{array}{l}\mathbf{E}_{\mathbf{a}}^{\neq} \\
\mathbf{k J} \mathbf{~ m o l}^{\mathbf{1}}\end{array}$ \\
\hline-117.34 & 47.23 & 82.19 & 48.17 \\
\hline
\end{tabular}

Experimental error $\pm 3 \%$ 


\subsection{Effect of Initially Added Product}

The effect of added hexacyanoferrate(II) product was studied also in the concentration range of $(2.0-12.0) \times 10^{-4}$ mol dm$~_{-3}$ at fixed concentrations of the oxidant, reductant, alkali and catalyst. It was found that HCF(II) did not have any significant effect on the rate of reaction.

\subsection{Polymerization Test}

The involvement of free radical species in the reaction was assayed by a polymerization test. A known quantity of acrylonitrile monomer was added initially to the reaction mixture in an inert atmosphere, with the result of progressive formation of a white precipitate in the whole reaction mixture indicating presence of free radical during reaction. When the experiment was repeated in the absence of Pym-F under similar conditions, the test was negative. This indicates that the reaction was routed through free radical path.

\section{Discussion}

Palladium(II) catalysis has been observed during various redox reactions [33-35]. In most of the studies using palladium(II) as a homogenous catalyst, it has been employed in the form of palladium(II) chloride. It is important to know the probable species of palladium(II) chloride in alkaline media which is mostly present as hydroxylated species, $\left[\mathrm{Pd}(\mathrm{OH})_{2} \mathrm{Cl}_{2}\right]^{2-},\left[\mathrm{Pd}(\mathrm{OH})_{3} \mathrm{Cl}\right]^{2-}$ and $\left[\mathrm{Pd}(\mathrm{OH})_{4}\right]^{2-}[34,35]$. The species $\left[\mathrm{Pd}(\mathrm{OH})_{3} \mathrm{Cl}\right]^{2-}$ and $\left[\mathrm{Pd}(\mathrm{OH})_{4}\right]^{2-}$ are not commonly found due to their insoluble characteristic. Hence, the $\left[\mathrm{Pd}(\mathrm{OH})_{2} \mathrm{Cl}_{2}\right]^{2-}$ complex ion (written as $\operatorname{Pd}(\mathrm{II})^{*}$ in the mechanism for brevity) has been assumed to be the reactive species in the present study.

The oxidation of Pym-F substrate by HCF in alkaline medium did not occur in the absence of a catalyst while it proceeded in a measurable quantities in the presence of small amounts of palladium(II) catalyst. The reaction has a stoichiometry of 2:1, i.e., two moles of hexacyanoferrate(III) requires one mole of Pym-F. The order with respect to $[\mathrm{HCF}]$ and $[\mathrm{Pd}(\mathrm{II})]$ was found to be unity and less than unity with respect to $[\mathrm{Pym}-\mathrm{F}]$ and $\left[\mathrm{OH}^{-}\right]$. Increasing the reaction rate with the increase in $\left[\mathrm{OH}^{-}\right]$ suggests deprotonation of Pym-F substrate. The rate is not considerably affected by $\mathrm{HCF}(\mathrm{II})$ suggesting that the probability of any fast equilibrium with the product preceding the rate-determining step was ruled out. The ratedetermining step should be irreversible as is generally the case for one electron oxidants [36] and the oxidation takes place through generation of a free radical as obtained experimentally. The effect of ionic strength and dielectric constant on the reaction rate suggests that similarly charged species are interacting in the rate-determining step [37, 38].

On the other hand, the less than unit with respect to Pym-F concentration may be due to formation of a complex (C) between $\mathrm{Pd}(\mathrm{II})^{*}$ species and deprotonated Pym-F species in a pre-equilibrium step. Complex formation was proved kinetically by the non-zero intercept of the $[\mathrm{Pd}(\mathrm{II})] / k_{\mathrm{C}}$ versus
1/[Pym-F] plot (Figure 7) in favor of possible formation of an intermediate complex between the oxidant and substrate [39]. Then, the oxidant HCF attack the formed complex in a slow (rate-determining) step to yield Pym-F free radical and $\mathrm{HCF}(\mathrm{II})$ with regeneration of the catalyst $\mathrm{Pd}(\mathrm{II})^{*}$. The radical intermediate reacts with another mole of the oxidant in a subsequent fast step to yield the final oxidation products. The results are accommodated in Scheme 1.

Again, it has been reported [40-42] that the entropy of activation $\left(\Delta S^{\ddagger}\right)$ tends to be more negative for reactions of an inner-sphere nature, whereas the reactions of positive $\Delta S^{\ddagger}$ values proceed via an outer-sphere mechanism. The obtained large negative values of $\Delta S^{\ddagger}$ (Table 2) suggests that the more plausible mechanism is one-electron transfer of inner-sphere nature. Furthermore, large negative values of $\Delta S^{\neq}$indicate that there is a decrease in the randomness during the oxidation process. This leads to the formation of compacted intermediate complex and such activated complex is more ordered than the reactants due to loss of degree of freedom. On the other hand, the positive value of $\Delta H^{\neq}$indicates that the complex formation is endothermic. Also, the large positive value of $\Delta G^{\neq}$suggests enhanced formation of the intermediate with raising temperature as well as to the nonspontaneity of the complex formation.

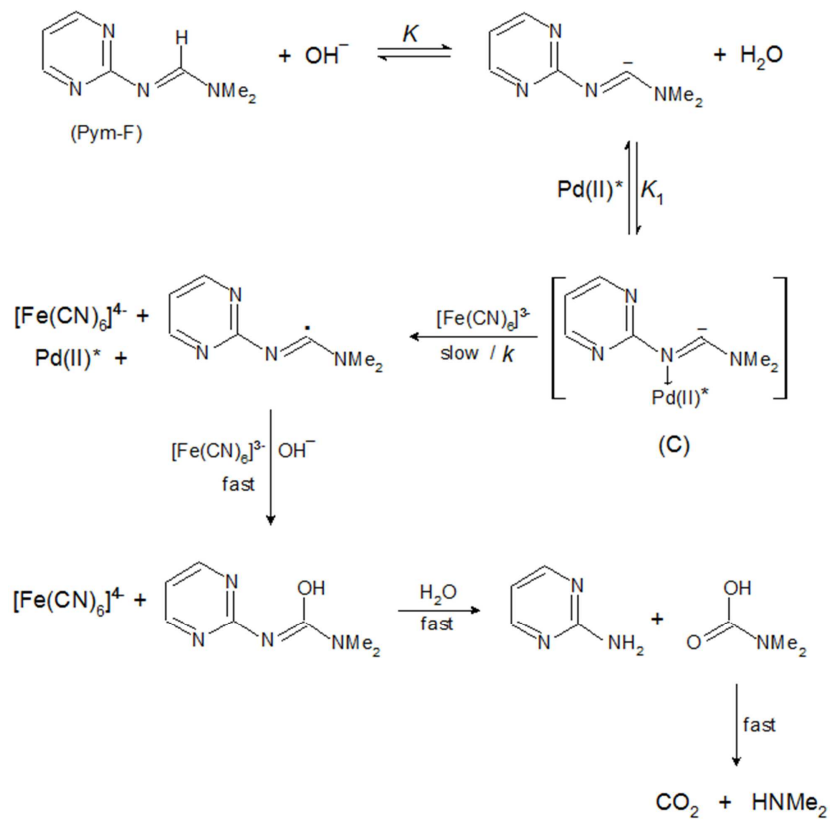

Scheme 1. Mechanism of Pd(II)-catalyzed oxidation of Pym-F by HCF in alkaline medium.

The suggested mechanism leads to the following rate law expression (see Appendix A),

$$
\text { Rate }=\frac{k K K_{1}[\mathrm{Pym}-\mathrm{F}][\mathrm{HCF}][\mathrm{Pd}(\mathrm{II})]\left[\mathrm{OH}^{-}\right]}{\left.1+K\left[\mathrm{OH}^{-}\right]+K K_{1} \mathrm{Pym}-\mathrm{F}\right]\left[\mathrm{OH}^{-}\right]}
$$

Under pseudo-first order condition,

$$
\text { Rate }=\frac{-d[\mathrm{HCF}]}{d t}=k_{C}[\mathrm{HCF}]
$$


Therefore,

$$
k_{C}=\frac{\text { Rate }}{[\mathrm{HCF}]}=\frac{k K K_{1}[\mathrm{Pym}-\mathrm{F}][\mathrm{Pd}(\mathrm{II})]\left[\mathrm{OH}^{-}\right]}{1+K\left[\mathrm{OH}^{-}\right]+K K_{1}[\mathrm{Pym}-\mathrm{F}]\left[\mathrm{OH}^{-}\right]}
$$

Equation (3) can be rearranged to the following forms, which is suitable for verification,

$$
\begin{gathered}
\frac{[\mathrm{Pd}(\mathrm{II})]}{k_{\mathrm{C}}}=\left(\frac{1}{k K K_{1}\left[\mathrm{OH}^{-}\right]}+\frac{1}{k K_{1}}\right) \frac{1}{[\mathrm{Pym}-\mathrm{F}]}+\frac{1}{k} \\
\frac{[\mathrm{Pd}(\mathrm{II})]}{k_{\mathrm{C}}}=\left(\frac{1}{k K K_{1}[\mathrm{Pym}-\mathrm{F}]}\right) \frac{1}{\left[\mathrm{OH}^{-}\right]}+\frac{1}{k K_{1}[\mathrm{Pym}-\mathrm{F}]}+\frac{1}{k}
\end{gathered}
$$

Regarding to Eqs. (4) and (5), plots of $[\mathrm{Pd}(\mathrm{II})] / k_{\mathrm{C}}$ versus $1 /[\mathrm{Pym}-\mathrm{F}]$ at constant $\left[\mathrm{OH}^{-}\right]$and $[\mathrm{Pd}(\mathrm{II})] / k_{\mathrm{C}}$ versus $1 /\left[\mathrm{OH}^{-}\right]$at constant [Pym-F] should be linear with positive intercepts. The experimental results satisfied these requirements as shown in Figures 7 and 8, respectively. The value of the rate constant of the slow step $(k)$ obtained as reciprocal of intercept of $[\mathrm{Pd}(\mathrm{II})] / k_{\mathrm{C}}$ versus $1 /[\mathrm{Pym}-\mathrm{F}]$ plot was found to be $1.68 \times 10^{3} \mathrm{~s}^{-1}$. Also, the values of the equilibrium constants associated with the mechanistic Scheme (1) $\left(K\right.$ and $\left.K_{1}\right)$ are evaluated from the slope and intercept of Figures 7 and 8 and were found to be 1.32 and $71.43 \mathrm{dm}^{3} \mathrm{~mol}^{-1}$, respectively.

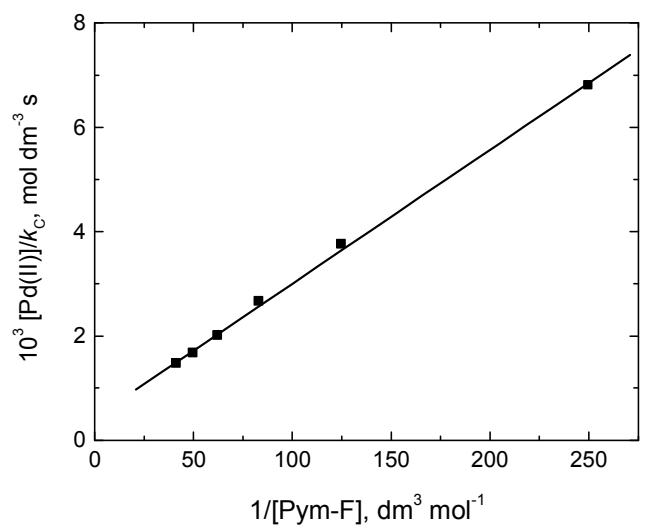

Figure 7. Verification of equation (4) in the Pd(II)-catalyzed oxidation of Pym- $\mathrm{F}$ by $\mathrm{HCF}$ in alkaline medium. $[\mathrm{HCF}]=7.0 \times 10^{-4},\left[\mathrm{OH}^{-}\right]=0.5$ and $\mathrm{I}=$ $1.0 \mathrm{~mol} \mathrm{dm} \mathrm{m}^{-3}$ at $25^{\circ} \mathrm{C}$.

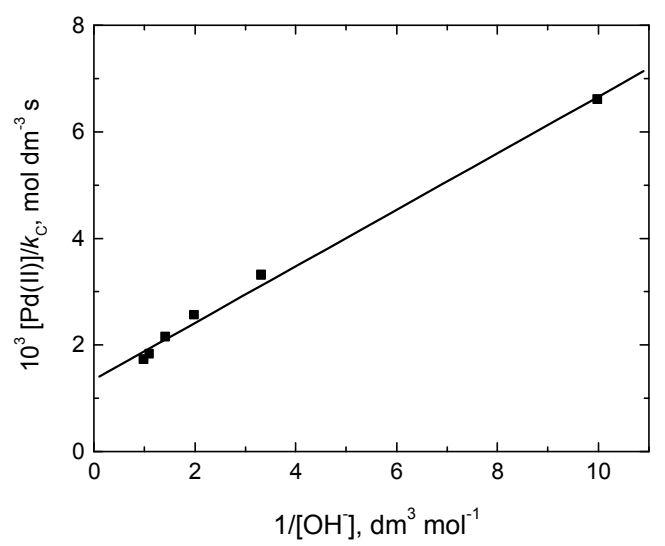

Figure 8. Verification of equation (5) in the Pd(II)-catalyzed oxidation of Pym-F by HCF in alkaline medium. $[\mathrm{HCF}]=7.0 \times 10^{-4},[\mathrm{Pym}-\mathrm{F}]=1.2 \times 10^{-}$ ${ }^{2}$ and $\mathrm{I}=1.0 \mathrm{~mol} \mathrm{dm} m^{-3}$ at $25^{\circ} \mathrm{C}$.

\section{Conclusions}

The catalytic effect of palladium(II) catalyst on kinetics of oxidation of $N, N$-dimethyl- $N$ '-(pyrimidin-2-yl) formamidine by hexacyanoferrate(III) has been investigated in aqueous alkaline medium. The reaction did not proceed in the absence of Pd(II) catalyst. The final oxidation products are identified as 2-aminopyrimidine, dimethylamine and carbon dioxide. The rate law expression associated with the reaction mechanism is derived and the reaction constants involved in the different steps of the mechanism are calculated. The activation parameters with respect to the rate-determining step have been computed and discussed.

\section{Appendix A.}

\section{Derivation of the Rate Law Expression}

According to the proposed mechanistic Scheme,

$$
\begin{aligned}
& \text { Rate }=\frac{-d[\mathrm{HCF}]}{d t}=k[C][\mathrm{HCF}] \\
& K=\frac{\left[\mathrm{Pym}-\mathrm{F}^{-}\right]}{[\mathrm{Pym}-\mathrm{F}]\left[\mathrm{OH}^{-}\right]},\left[\mathrm{Pym}-\mathrm{F}^{-}\right]=K[\mathrm{Pym}-\mathrm{F}]\left[\mathrm{OH}^{-}\right] \\
& K_{1}=\frac{[\mathrm{C}]}{\left[\mathrm{Pym}-\mathrm{F}^{-}\right][\mathrm{Pd}(\mathrm{II})]},[\mathrm{C}]=K_{1}\left[\mathrm{Pym}^{-\mathrm{F}^{-}}\right][\mathrm{Pd}(\mathrm{II})] \\
& {[\mathrm{C}]=K K_{1}[\mathrm{Pym}-\mathrm{F}]\left[\mathrm{OH}^{-}\right][\mathrm{Pd}(\mathrm{II})]}
\end{aligned}
$$

Substituting Eq. (A3) into Eq. (A1) leads to,

$$
\text { Rate }=k K K_{1}[\mathrm{Pym}-\mathrm{F}]\left[\mathrm{OH}^{-}\right][\mathrm{Pd}(\mathrm{II})][\mathrm{HCF}]
$$

The total concentration of MAPF is given by,

$$
[\text { Pym-F }]_{\mathrm{T}}=[\text { Pym-F }]_{\mathrm{F}}+\left[\text { Pym-F}^{-}\right]+[\mathrm{C}]
$$

where ' $\mathrm{T}$ ' and ' $\mathrm{F}$ ' stand for total and free concentrations.

Substituting Eqs. (A2) and (A3) into Eq. (A5) and rearrangement gives,

$$
\begin{gathered}
{\left[\mathrm{Pym}_{-\mathrm{F}}\right]_{\mathrm{T}}=[\mathrm{Pym}-\mathrm{F}]_{\mathrm{F}}+K\left[\mathrm{Pym}^{\mathrm{F}}\right]\left[\mathrm{OH}^{-}\right]} \\
+K K_{1}[\mathrm{Pym}-\mathrm{F}]\left[\mathrm{OH}^{-}\right][\mathrm{Pd}(\mathrm{II})] \\
{\left[\mathrm{Pym}-\mathrm{F}_{\mathrm{T}}=\left[\mathrm{Pym}_{-\mathrm{F}}\right]_{\mathrm{F}}\left(1+K\left[\mathrm{OH}^{-}\right]+K K_{1}\left[\mathrm{OH}^{-}\right][\mathrm{Pd}(\mathrm{II})]\right)\right.}
\end{gathered}
$$

Therefore,

$$
[\mathrm{Pym}-\mathrm{F}]=\frac{[\mathrm{Pym}-\mathrm{F}]_{\mathrm{T}}}{1+K\left[\mathrm{OH}^{-}\right]+K K_{1}\left[\mathrm{OH}^{-}\right][\mathrm{Pd}(\mathrm{II})]}
$$

In view of low $[\mathrm{Pd}(\mathrm{II})]$, the third denominator term $K K_{1}[\mathrm{OH}][\mathrm{Pd}(\mathrm{II})]$ in the above equation can be neglected. Therefore, Eq. (A8) can be simplified to the following,

$$
[\mathrm{Pym}-\mathrm{F}]=\frac{[\mathrm{Pym}-\mathrm{F}]_{\mathrm{T}}}{1+K\left[\mathrm{OH}^{-}\right]}
$$




$$
\begin{gathered}
{[\mathrm{Pd}(\mathrm{II})]_{\mathrm{T}}=[\mathrm{Pd}(\mathrm{II})]_{\mathrm{F}}+[\mathrm{C}]} \\
{[\mathrm{Pd}(\mathrm{II})]_{\mathrm{T}}=[\mathrm{Pd}(\mathrm{II})]_{\mathrm{F}}\left(1+K K_{1}[\mathrm{Pym}-\mathrm{F}]\left[\mathrm{OH}^{-}\right]\right)} \\
{[\mathrm{Pd}(\mathrm{II})]_{\mathrm{F}}=\frac{[\mathrm{Pd}(\mathrm{II})]_{\mathrm{T}}}{1+K K_{1}[\mathrm{Pym}-\mathrm{F}]\left[\mathrm{OH}^{-}\right]}}
\end{gathered}
$$

Regarding to the concentration of $\mathrm{OH}^{-}$,

$$
\left[\mathrm{OH}^{-}\right]_{\mathrm{F}}=\left[\mathrm{OH}^{-}\right]_{\mathrm{T}}
$$

Substituting Eqs. (A9), (A12) and (A13) into Eq. (A4) (and omitting ' $\mathrm{T}$ ' and ' $\mathrm{F}$ ' subscripts) leads to,

$$
\begin{gathered}
\text { Rate }=\frac{k K K_{1}[\mathrm{Pym}-\mathrm{F}]\left[\mathrm{OH}^{-}\right][\mathrm{Pd}(\mathrm{II})][\mathrm{HCF}]}{\left(1+K\left[\mathrm{OH}^{-}\right]\right)\left(1+K K_{1}[\mathrm{Pym}-\mathrm{F}]\left[\mathrm{OH}^{-}\right]\right)} \\
\text {Rate }=\frac{k K K_{1}[\mathrm{Pym}-\mathrm{F}]\left[\mathrm{OH}^{-}\right][\mathrm{Pd}(\mathrm{II})][\mathrm{HCF}]}{1+K\left[\mathrm{OH}^{-}\right]+K K_{1}[\mathrm{Pym}-\mathrm{F}][\mathrm{OH}]+K^{2} K_{1}[\mathrm{Pym}-\mathrm{F}]\left[\mathrm{OH}^{-}\right]^{2}}
\end{gathered}
$$

The term $K^{2} K_{1}[\mathrm{Pym}-\mathrm{F}]\left[\mathrm{OH}^{-}\right]^{2}$ in the denominator of Eq. (A15) is negligibly small compared to unity in view of the low concentration of Pym-F used. Therefore Eq. (A15) can be written as,

$$
\text { Rate }=\frac{k K K_{1}[\mathrm{Pym}-\mathrm{F}]\left[\mathrm{OH}^{-}\right][\mathrm{Pd}(\mathrm{II})][\mathrm{HCF}]}{1+K\left[\mathrm{OH}^{-}\right]+K K_{1}[\mathrm{Pym}-\mathrm{F}]\left[\mathrm{OH}^{-}\right]}
$$

Under pseudo-first order condition, the rate-law can be expressed by Eq. (A17),

$$
\text { Rate }=\frac{-d[\mathrm{HCF}]}{d t}=k_{C}[\mathrm{HCF}]
$$

Therefore, comparing Eqs. (A16) and (A17), the following relationship is obtained,

$$
k_{C}=\frac{\text { Rate }}{[\mathrm{HCF}]}=\frac{k K K_{1}[\mathrm{Pym}-\mathrm{F}][\mathrm{Pd}(\mathrm{II})]\left[\mathrm{OH}^{-}\right]}{1+K\left[\mathrm{OH}^{-}\right]+K K_{1}[\mathrm{Pym}-\mathrm{F}]\left[\mathrm{OH}^{-}\right]}
$$

Equation (A16) can be rearranged to the following forms, which is suitable for verification,

$$
\begin{gathered}
\frac{[\mathrm{Pd}(\mathrm{II})]}{k_{\mathrm{C}}}=\left(\frac{1}{k K K_{1}\left[\mathrm{OH}^{-}\right]}+\frac{1}{k K_{1}}\right) \frac{1}{[\mathrm{Pym}-\mathrm{F}]}+\frac{1}{k} \\
\frac{[\mathrm{Pd}(\mathrm{II})]}{k_{\mathrm{C}}}=\left(\frac{1}{k K K_{1}[\mathrm{Pym}-\mathrm{F}]}\right) \frac{1}{\left[\mathrm{OH}^{-}\right]}+\frac{1}{k K_{1}[\mathrm{Pym}-\mathrm{F}]}+\frac{1}{k}
\end{gathered}
$$

\section{References}

[1] Joule, John A.; Mills, Keith, eds. (2010). Heterocyclic Chemistry (5th ed.). Oxford: Wiley. p. 250.

[2] Nuevo M, Milam SN, Sandford SA, Elsila JE, Dworkin JP (2009) Formation of uracil from the ultraviolet photoirradiation of pyrimidine in pure $\mathrm{H}_{2} \mathrm{O}$ ices. Astrobiology 9: 683-695.
[3] Leung VSK, Chan TYK, Yeung VTF (1999) Ami-traz poisining in humans, Clinical Toxicol. 37: 513-514.

[4] Nakayama A, Sukekawa M, Eguchi Y (1997) Stereochemistry and active conformation of a novel insecticide Acetamiprid. Pesticide Sci. 51: 157-164.

[5] Beeman RW, Matsumura F (1973) Chlordimeform: a pesticide acting upon amine regulatory mechanisms. Nature 242: 273274.

[6] Aziz AA, Knowles CO (1973) Inhibition of monoamine oxidase by the pesticides chlordimeform and related compounds. Nature 242: 417-418.

[7] Fawzy A. (2016) Kinetics and mechanism of uncatalyzed and ruthenium(III)-catalyzed oxidation of formamidine derivative by hexacyanoferrate(III) in aqueous alkaline medium. J. Chem. Sci. In press.

[8] Fawzy A, Zaafarany IA, Yarkandi N, Al-Bonayan A, Almallah Z (2016) Kinetic and mechanism of oxidation of methylaminopyrazole formamidine by alkaline hexacyanoferrate(III) and the effect of divalent transition metal ions. Sci. J. Chem.1:1-8.

[9] Padhye S, Kaufman GB (1985) Transition metal complexes of semicarbazones and thiosemicarbazones. Coord. Chem. Rev. 63: 127-160.

[10] Asiri AM, Khan SA (2010) Palladium(II) complexes of NS donor ligands derived from steroidal thiosemicarbazones as antibacterial agents. Molecules 15: 4784-4791.

[11] Fawzy A (2015) Kinetics and mechanistic approach to the oxidative behavior of biological anticancer platinum(IV) complex towards L-asparagine in acid medium and the effect of copper(II) catalyst. Int. J. Chem. Kinet. 47: 1-12.

[12] Fawzy A, Zaafarany IA (2015) Mechanistic investigation of copper(II)-catalyzed oxidation of L-asparagine by hexachloroplatinate(IV) in aqueous alkaline medium: a kinetic approach.J. Multidisc. Eng. Sci. Technol. 2: 1038-1045.

[13] Asghar BH, Altass HM, Fawzy A (2016) Silver(I)-catalysis of oxidative deamination and decarboxylation of L-asparagine and L-histidine by platinum(IV) in perchloricacid solutions: acomparative kinetics study. J. Env. Chem. Eng. 4: 617-623.

[14] Asghar BH, Altass HM, Fawzy A (2015) Transition metal ions-catalyzed oxidation of L-asparagine by platinum(IV) in acid medium: a kinetic and mechanistic study. Transition Met. Chem. 40: 587-594.

[15] Kelson EP, Phengsy PP (2000) Kinetic study of 2-propanol and benzyl alcohol oxidation by alkaline hexacyanoferrate(III) catalysed by a terpyridyl ruthenium complex. Int. J. Chem. Kinet. 32: 760-770.

[16] Vovk AI, Muraveva IV, Kukhar VP, Baklan VF (2000) Kinetics of oxidation of vitamin B1 and its Oacyl analogs with ferricyanide. A mechanistic model of thiamin-binding protein. Russ. J. Gen. Chem. 70: 1108-1112.

[17] Speakman PT, Waters WA (1955) Kinetic features of the oxidation of aldehydes, ketones and nitroparaffins with alkaline ferricyanide. J. Chem. Soc. 40-50.

[18] Jose TP, Nandibewoor ST, Tuwar SM (2006) Kinetics and mechanism of oxidation of vanillin by hexacyanoferrate(III) in aqueous alkaline medium. J. Solution Chem. 35: 51-62. 
[19] Singh VN, Singh MP, Saxena BBL (1970) Kinetics and mechanism of alkaline ferricyanide oxidation of acetone and ethyl methyl ketone. Indian J. Chem. 8: 529-532.

[20] Leal JM, Garcia B, Domingo PL (1998) Outer-sphere hexacyanoferrate(III) oxidation of organic substrates. Coord. Chem. Rev. 173: 79-131.

[21] Jose TP, Angadi MA, Salunke MS, Tuwar SM (2008) Oxidative study of gabapentin by alkaline hexacyanoferrate(III) in room temperature in presence of catalytic amount of Ru(III). A mechanistic approach. J. Mol. Struct. 892: 121-124.

[22] Sharanabasamma K, Angadi MA, Salunke MS, Tuwar SM (2009) Osmium(VIII) catalysed oxidative cleavage of pyrrolidine ring in L-proline by hexacyanoferrate(III) in alkaline media. Ind. Eng. Chem. Res. 48: 10381-10386.

[23] Goel A, Sharma S (2010) Mechanistic study of the oxidation of L-phenylalanine by hexacyanoferrate(III) catalyzed by iridium(III) in aqueous alkaline medium, Transition Met. Chem. 35: 549-554.

[24] Devra V, Yadav MB (2012) Kinetics and mechanism of osmium(VIII) catalyzed oxidation of valine by hexacyanoferrate in alkaline medium, Rassian J. Chem. 5: 6773.

[25] Upadhyay SK, MC agrawal (1977) Kinetics of Os(VIII)catalyzed alkaline hexacyanoferrate(III) oxidation of some $\alpha$ amino acids in presence of excess of ferricyanide, Ind. J. Chem., 15A: 709-712.

[26] Jose TP, Nandibewoor ST, Tuwar SM (2006) Osmium(VIII) catalyzed oxidation of a sulfur containing amino acid - A kinetic and mechanistic Approach. J. Sulfur Chem., 27: 25-36.

[27] Farokhi SA, Nandibewoor ST (2003) Kinetic, mechanistic and spectral studies for the oxidation of sulfanilic acid by alkaline hexacyanoferrate(III). Tetrahedron 59: 7595-7601.

[28] Fawzy A, Shaaban MR (2014) Kinetic and mechanistic investigations on the oxidation of N'-heteroaryl unsymmetrical formamidines by permanganate in aqueous alkaline medium. Transition Met. Chem. 39: 379-386.

[29] Asghar BH, Fawzy A (2014) Kinetic, mechanistic, and spectroscopic studies of permanganate oxidation of azinylformamidines in acidic medium, with autocatalytic behavior of manganese(II). J. Saudi Chem. Soc. in press.
[30] Jeffery GH, Bassett J, Mendham J, Denney RC (1996) Text Book of Quantitative Chemical Analysis, 5th ed.; ELBS Longman: Essex, pp. 384.

[31] Vogel AI (1973) Text book of practical organic chemistry including quantitative organic analysis, 3rd edn, $332 \mathrm{pp}$. ELBS, Longman.

[32] Feigl F (1975) Spot tests in organic analysis, 195 pp. Elsevier, New York.

[33] Fawzy A. (2016) Kinetics and mechanism of uncatalyzed and ruthenium(III)-catalyzed oxidation of formamidine derivative by hexacyanoferrate(III) in aqueous alkaline medium. J. Chem. Sci. in press.

[34] Wan WK, Zaw K, Henry PM (1988) Oxidation of olefins by palladium(II). 11. Kinetics and mechanism of the oxidation of allyl alcohol by $\mathrm{PdCl}_{4}{ }^{2-}$ in aqueous solution. Organometallics 7:1677-1683; Nabivaneis BI, Kalabina LV, Kudritskayi LN (1971) Russ. J. Inorg. Chem. 16: 1736.

[35] Koli BI, Nandibewoor ST (2009) Kinetics and mechanism of palladium(II) catalysed oxidation of dimethyl sulfoxide by alkaline periodate. Indian J. Chem. 48A: 958-963.

[36] Leal JM, Domingo PL, Garcla B, Ibeas S (1993) Alkali metal ion catalysis of the oxidation of L-ascorbic acid by hexacyanoferrate(III) in strongly acidic media. J. Chem. Soc. Faraday Trans. 89: 3571-3577.

[37] Frost AA, Person RG (1973) Kinetics and mechanism, 147 pp. Wiley Eastern, New Delhi.

[38] Amis ES (1966) Solvent effect on reaction rates and mechanism, pp. 28, Academic Press, New York.

[39] Michaelis L, Menten ML (1913) The kinetics of invertase action. Biochem. Z. 49: 333-369.

[40] Hicks KW, Toppen DL, Linck RG (1972) Inner-sphere electron-transfer reactions of vanadium(II) with azidoamine complexes of cobalt(III). Inorg. Chem. 11: 310-315.

[41] Sutin N (1968) Free energies, barriers, and reactivity patterns in oxidation-reduction reactions. Acc. Chem. Res. 1: 225-231.

[42] Freeman F (1981) Permanganate ion oxidations. 13. Soluble manganese(IV) species in the oxidation of $2,4(1 \mathrm{H}, 3 \mathrm{H})$ pyrimidinediones (uracils). J. Am. Chem. Soc. 103: 11541158. 